\title{
Familial reactive perforating collagenosis
}

INSERM

\section{Source}

INSERM. (1999). Orphanet: an online rare disease and orphan drug data base. Familial reactive perforating collagenosis. ORPHA:79147

Familial reactive perforating collagenosis is a very rare genetic skin disease characterized by transepidermal elimination of collagen fibers presenting as recurrent spontaneously involuting keratotic papules or nodules. 